\title{
Virus strain discrimination using recombinant antibodies
}

\author{
N. Boonham* and I. Barker \\ Central Science Laboratory, Sand Hutton, York YO41 \\ 1LZ, UK \\ Tel.: +44 1904 462000; Fax: +44 1904 462111; \\ E-mail: n.boonham@csl.gov.uk.
}

\begin{abstract}
Most routine testing for plant viruses is currently carried out using monoclonal and polyclonal antibodies. Traditional methods of antibody production however can be time consuming and require the use of expensive cell culture facilities. Recombinant antibody technology however is starting to make an impact in this area, enabling the selection of antibody fragments in a few weeks compared with the many months associated with traditional methods and requires only basic microbiological facilities. Single chain Fv antibody fragments ( $\mathrm{scFv}$ ) have been selected from a synthetic phage-antibody library by affinity selection with purified Potato virus $Y$, ordinary strain $\left(\mathrm{PVY}^{\mathrm{O}}\right)$. The $\mathrm{scFv}$ selected was specific for $\mathrm{PVY}$ and detected 7 out of 9 isolates of $\mathrm{PVY}^{\mathrm{O}}$ whilst it did not detect 15 isolates from the closely related necrotic strains $\mathrm{PVY}^{\mathrm{N}}$ and $\mathrm{PVY} \mathrm{YTN}^{\mathrm{NT}}$. In ELISA the scFv could be used to detect virus at concentrations of $50 \mathrm{ng} / \mathrm{ml}$ in plant sap and was shown to have similar limits of detection as commercially available PVY monoclonal antibodies. These results highlight the potential of the technology for the selection of strain specific antibodies with an affinity and assay sensitivity similar to traditional monoclonal antibodies and their use in viral diagnostics.
\end{abstract}

\section{Introduction}

PVY is the most economically important virus infecting potato; in conjunction with Potato leaf roll virus and Potato virus $X$ it is responsible for crop losses in potato amounting to $£ 30-50$ million per year [3]. The most important method of control for PVY is the planting of healthy seed potatoes, which is monitored by

\footnotetext{
*Corresponding author.
}

visual inspection and testing for the presence or absence of PVY by ELISA, following the growing of tubers [5]. The object of the work was to investigate the use of phage displayed antibody technology to obtain single chain Fv antibody fragments ( $\mathrm{scFv}$ ) which detect $\mathrm{PVY}^{\mathrm{O}}$ but not $\mathrm{PVY}^{\mathrm{N}}$.

\section{Materials and methods}

The library used was a single chain variable fragment ( $\mathrm{scFv}$ ) phage library, obtained from the MRC, Cambridge (The Griffin Library [1]). This library contains a large synthetic repertoire of $1.2 \times 10^{9}$ clones (Fig. 1). Single chain fragments were selected following 3 rounds of selection against immobilised purified virus, following protocols supplied by the MRC.

\section{Results}

Following screening, scFv were selected which were specific for PVY and could be used in ELISA (using readily available antibodies) to detect as little as $5 \mathrm{ng}$ of purified virus in plant sap (Fig. 2).

The $\mathrm{scFv}$ was shown to be specific for the coat protein by western blotting (Fig. 3) and can detect 7 out of 9 isolates of $\mathrm{PVYO}$ whilst being unable to detect 15 isolates of PVY ${ }^{\mathrm{N}}$ by ELISA.

\section{Discussion}

Using phage display technology it should be possible to select antibody fragments that detect virtually any antigen [4]. Indeed a number of such reagents have been selected for the plant viral antigens CMV and PLRV $[2,6]$. An important consideration in viral diagnostics is not simply the detection of the virus, but also its differentiation from closely related strains of the 


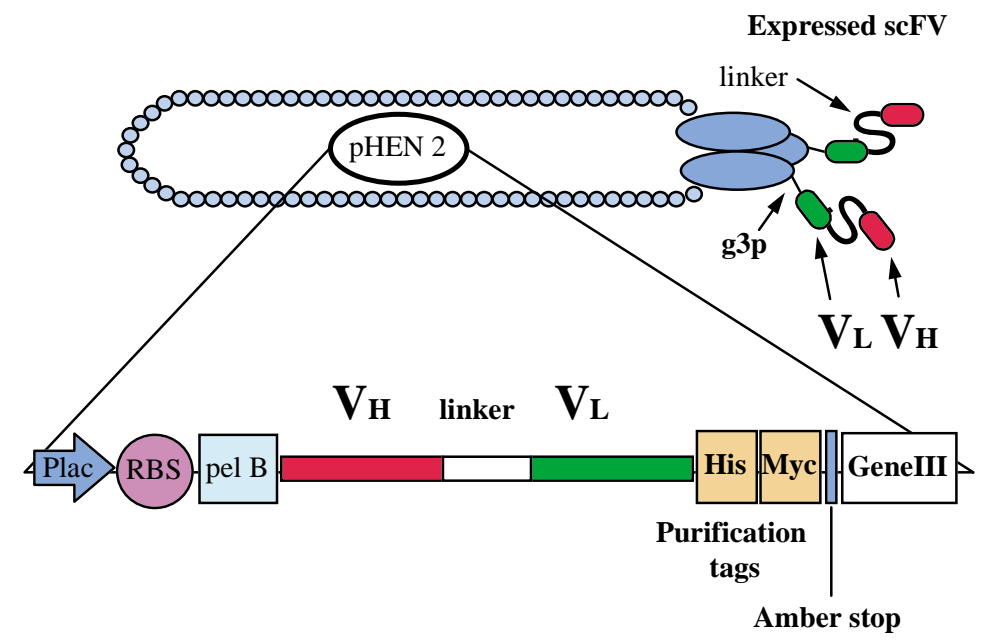

Fig. 1. The Griffin Library.

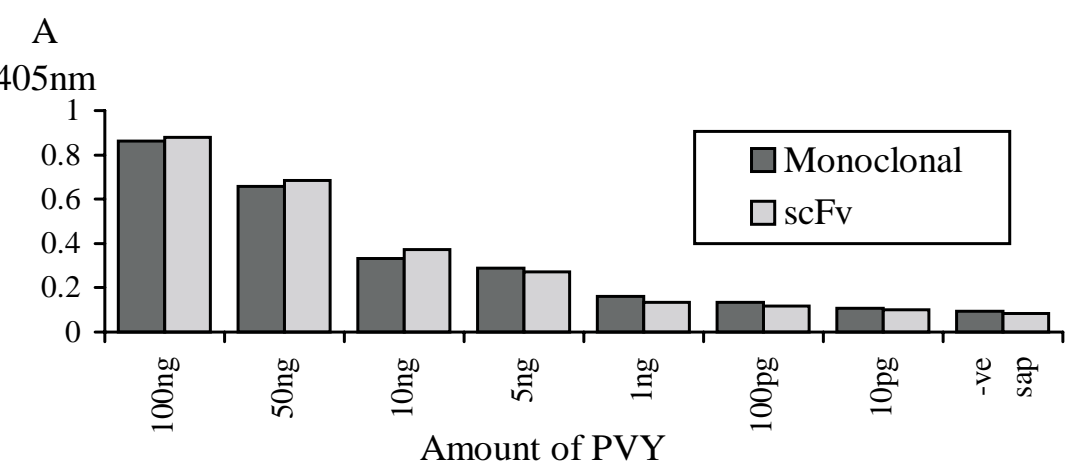

Fig. 2. Graph showing the absorbance (405 nm) vs. the PVY concentration in sap (trapped with polyclonal), comparing an scFv and commercial PVY monoclonal.

same virus; for example the separation of the common and necrotic strains of PVY.

We have shown it is possible to select antibody fragments, which show a similar limit of detection in ELISA to that of monoclonal antibodies, directly from large phage displayed libraries without the need for postselection modification. We have also shown that it is possible to select for fragments that show strain differentiation. Our scFvs detect 7 out of $9 \mathrm{PVY}^{\mathrm{O}}$ isolates but do not cross react with any of the isolates of $P V Y^{N}$ or PVY ${ }^{N T N}$ tested. Such discrimination between $\mathrm{PVY}^{\mathrm{O}}$ and $\mathrm{PVY}^{\mathrm{N}} / \mathrm{PVY} \mathrm{NTN}^{\mathrm{N}}$ has not been possible with many monoclonal antibodies.

This work has demonstrated that by using a library with a large synthetic repertoire it is possible to select for fragments which have similar assay sensitivity to that of monoclonal antibodies, and also that it is possible to select for fragments exhibiting strain specificity, an important consideration in viral diagnostics. The fragments generated can be easily incorporated into ELISA systems without any further cloning steps.

\section{Acknowledgments}

We would like to thank Fiona Sait (MRC, Cambridge) for supplying the phage library. This work was funded by MAFF Plant Health Division.

\section{References}

[1] A.D. Griffiths, S.C. Williams, O. Hartley, I.M. Tomlinson, P. Waterhouse, W.L. Crosby, R. Kontermann, P.T. Jones, N.M. Low, T.J. Allison, D. Prospero, H.R. Hoogenboom, A. Nissim, J.P.L. Cox, J.L. Harrison, E.G. Zaccolo and G. Winter, Isolation of high affinity human antibodies directly from large synthetic repertoires, The EMBO journal 13 (1994), 3245-3260. 


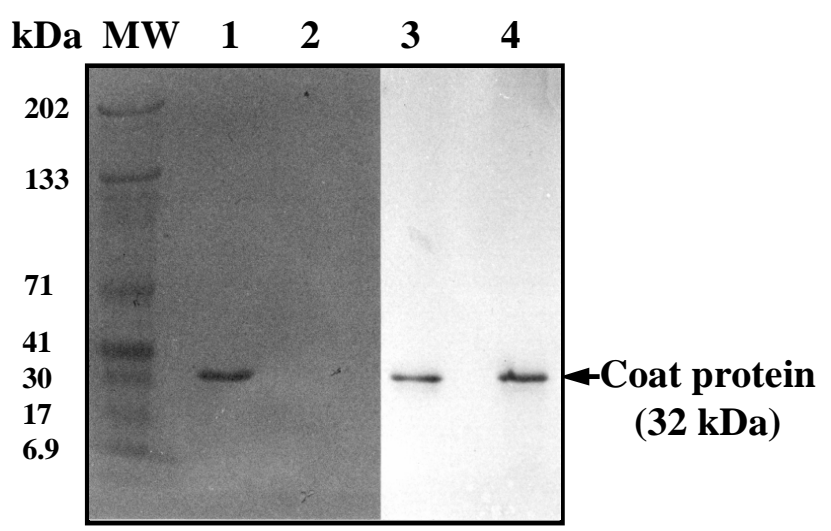

Fig. 3. Western blot analysis of purified PVY using scFv, Lane $1+3$ PVY-O, Lane $2+4$ PVY-N. Lane $1+2$, western blot, Lane $3+4$ silver stained PAGE gel.

[2] K. Harper, R.J. Kerschbaumer, A. Seigler, S.M. Macintosh, G.H. Cowan, G. Himmler, M.A. Mayo and L. Torrance, A scFv-alkaline phosphatase fusion protein which detects potato leafroll luteovirus in plant extracts by ELISA, Journal of Virological Methods 63 (1997), 237-242.

[3] R. Hull, Rapid diagnosis of plant virus infections by spot hybridisation, Trends in biotechnology 2 (1984), 2.

[4] A. Nissim, H.R. Hoogenboom, I.M. Tomlinson, G. Flynn, C. Midgley, D. Lane and G. Winter, Antibody fragments from a single pot phage display library as immunochemical reagents, EMBO Journal 13 (1994), 692-698.

[5] H.J. Vetten, U. Ehlers and H.L. Paul, Detection of potato viruses $\mathrm{Y}$ and $\mathrm{A}$ in tubers by enzyme linked immunosorbant assay after natural and artificial break of dormancy, Phytopathologische Zeitschrift 108 (1983), 41-53.

[6] A. Ziegler, L. Torrance, M. Macintosh, G.H. Cowan and M.A. Mayo, Cucumber mosaic cucumovirus antibodies from a synthetic phage display library, Virology 214 (1995), 235-238. 


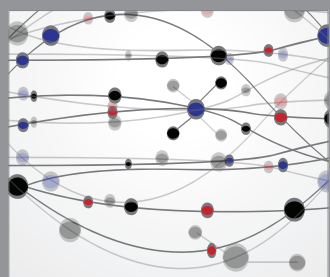

The Scientific World Journal
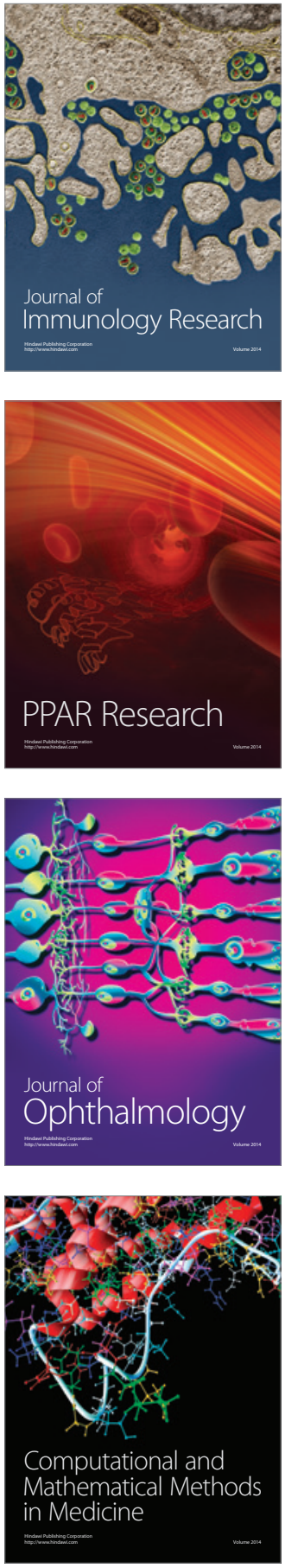

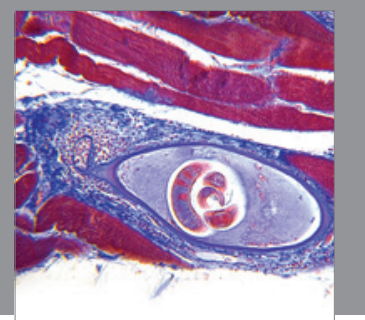

Gastroenterology

Research and Practice
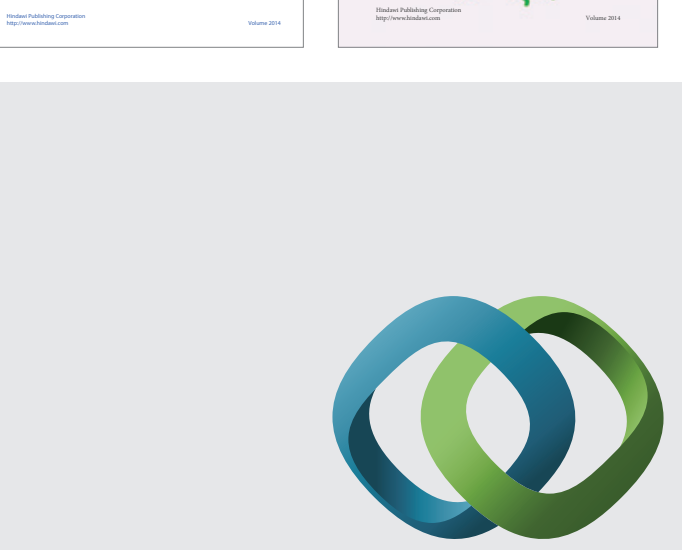

\section{Hindawi}

Submit your manuscripts at

http://www.hindawi.com
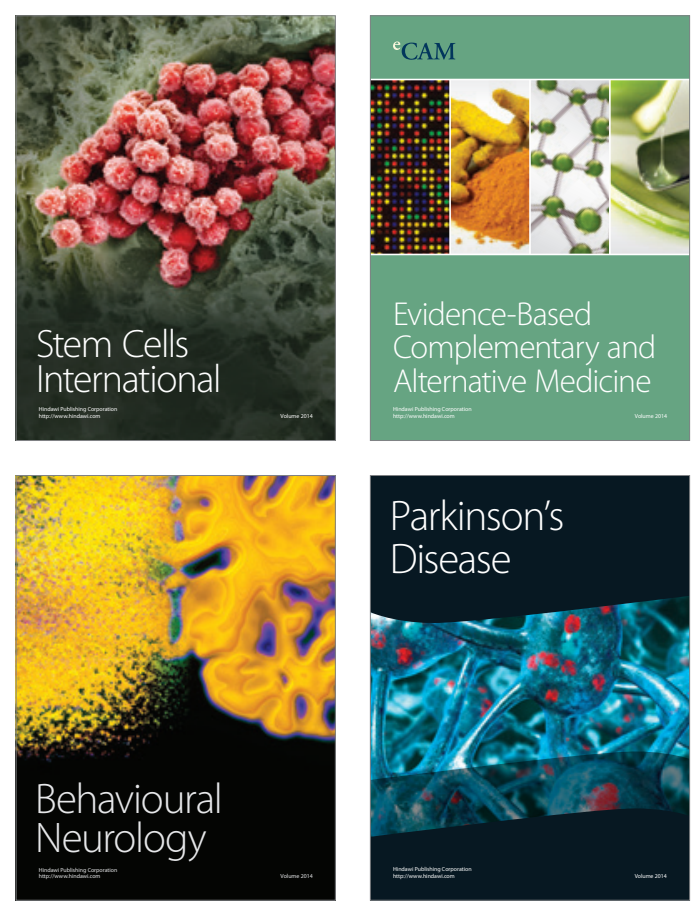

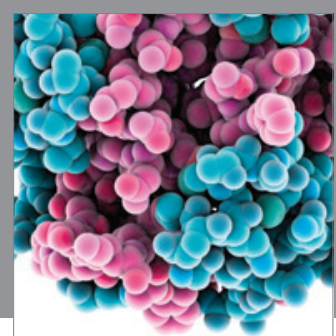

Journal of
Diabetes Research

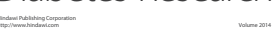

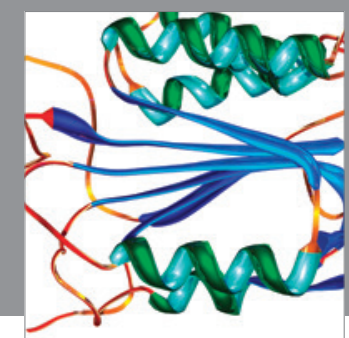

Disease Markers
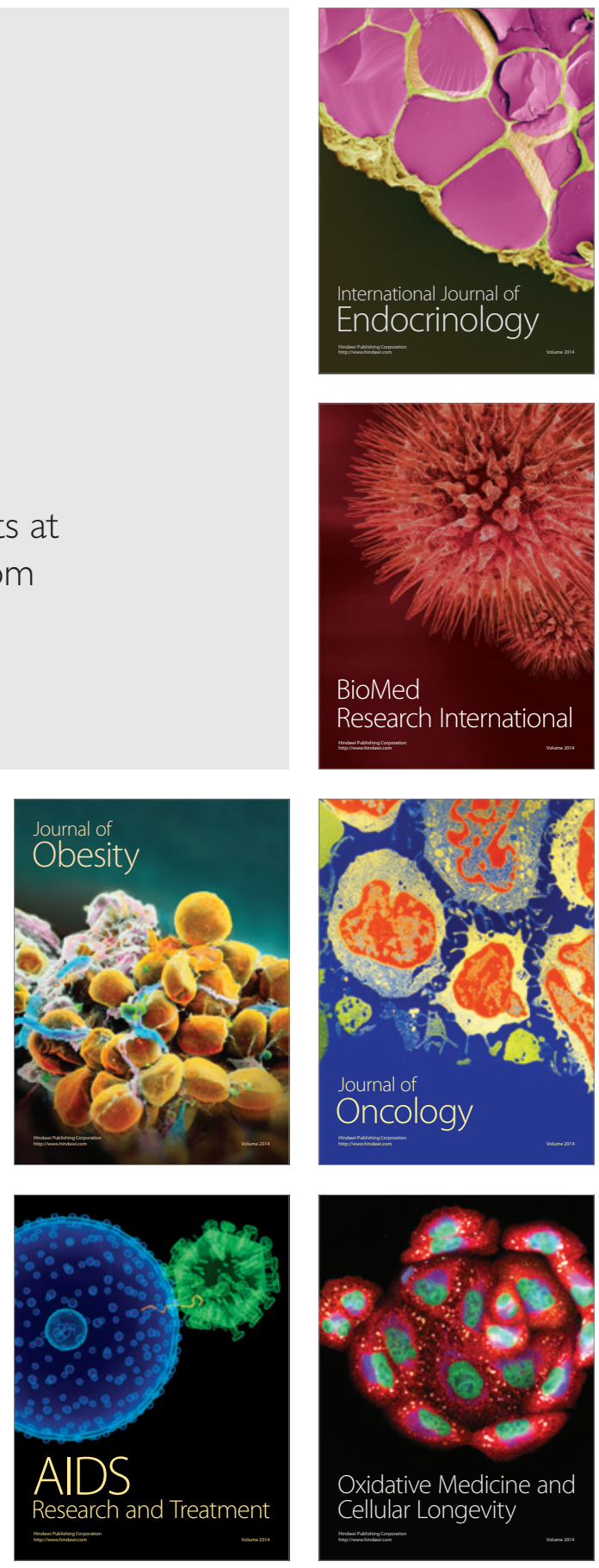